\title{
Exercise training improves heart rate recovery in women with breast cancer
}

\author{
Francesco Giallauria ${ }^{1 *}$, Luigi Maresca ${ }^{1}$, Alessandra Vitelli ${ }^{1}$, Maria Santucci de Magistris ${ }^{2}$, Paolo Chiodini ${ }^{3}$, \\ Amalia Mattiello², Marco Gentile², Maria Mancini ${ }^{1}$, Alessandra Grieco ${ }^{1}$, Angelo Russo ${ }^{1}$, Rosa Lucci', \\ Giorgio Torella ${ }^{1}$, Franco Berrino ${ }^{4}$, Salvatore Panico ${ }^{2}$ and Carlo Vigorito ${ }^{1}$
}

\begin{abstract}
Purpose: To determine whether exercise training improves autonomic function in women with breast cancer (BC). Methods: Fifty-one patients (aged between 39 and 72 years) with a history of primary invasive BC within the previous 5 years and enrolled in the Mediterranean diet-based DIANA (Diet and Androgens)- 5 Trial were subdivided in two groups: a ET group $(n=25)$ followed a formal ET program of moderate intensity (3 session/week on a bicycle at $60-70 \% \mathrm{VO}_{2 \text { peak }}$ for 3 months, followed by one session/week until 1-year follow-up), while a control group ( $\left.n=26\right)$ did not perform any formal ET. At baseline and after 1-year, all patients underwent cardiopulmonary exercise stress test (CPET). Heart rate recovery (HRR) was calculated as the difference between heart rate at peak exercise and heart rate at first minute of the cool-down period.
\end{abstract}

Results: There were no significant differences between groups in baseline anthropometrical, BC characteristics, metabolic profile, CPET parameters and HRR. Compared to controls, at 1-year follow-up ET group showed a significant improvement in $\mathrm{VO}_{2 \text { peak }}$ (from $12.6 \pm 3.0$ to $14.5 \pm 3.3 \mathrm{ml} / \mathrm{kg} / \mathrm{min}, \mathrm{p}<0.001 ; \mathrm{p}<0.001$ between groups); and in HRR (from $17.6 \pm 6.4$ to $23.0 \pm 8.3$ beats/min, $p<0.001 ; p<0.001$ between groups). In ET group the changes in HRR directly correlated with changes in $\mathrm{VO}_{2 \text { peak }}(r=0.58, p=0.002)$.

Conclusions: Moderate intensity exercise training in $\mathrm{BC}$ survivors is associated with improvement of autonomic function. Whether the improvement of sympatho-vagal balance may favorably modulate some of the pathophysiological mechanisms implied in cancer evolution need further investigation.

Keywords: Cancer, Breast cancer, Exercise training, Autonomic function, Heart rate recovery, Cardiopulmonary exercise testing

\section{Background}

Breast cancer $(\mathrm{BC})$ is the most common cancer and cause of death in women worldwide. Diet and physical activity play a pivotal role on occurrence of BC (http://www. ncbi.nlm.nih.gov/pubmed/?term $=$ diet + and + breast + c ancer+and+meta-analysis; Ferrari et al. 2013; Buckland et al. 2013). Several studies have investigated and quite consistently reported a possible effect of physical activity on the incidence of primary BC (http://www.ncbi.nlm.

\footnotetext{
*Correspondence: giallauriafrancesco@gmail.com

${ }^{1}$ Division of Internal Medicine and Cardiac Rehabilitation, Department of Translational Medical Sciences, University of Naples "Federico II", Via S. Pansini 5, 80131 Naples, NA, Italy

Full list of author information is available at the end of the article
}

nih.gov/pubmed/?term $=$ physical+activity+and+breast +cancer+and+meta-analysis; Ibrahim and $\mathrm{Al} \mathrm{Homaidh}$ 2011; Ballard-Barbash et al. 2012; McTiernan 2008); and secondary prevention studies after BC diagnosis consistently showed that the level of physical activity of BC women was correlated to an improvement in several cancer-related outcomes. In addition, exercise intervention studies have also suggested that a formal program of exercise training is also able to improve several cancerrelated outcomes in BC survivors (Spence et al. 2010; Gleeson et al. 2011; Goh et al. 2012).

Previous studies showed that autonomic nervous system imbalance is associated with mortality in patients with cardiovascular disease (CVD) (Freeman et al. 2006).

\section{Springer}

(c) 2015 Giallauria et al. This article is distributed under the terms of the Creative Commons Attribution 4.0 International License (http://creativecommons.org/licenses/by/4.0/), which permits unrestricted use, distribution, and reproduction in any medium, provided you give appropriate credit to the original author(s) and the source, provide a link to the Creative Commons license, and indicate if changes were made. 
The heart rate response to, and recovery from, a bout of exercise is mediated by the dynamic interaction between the sympathetic and parasympathetic components of the autonomic nervous system (Freeman et al. 2006). Specifically, greater sympathetic tone predominates as heart rate increases during exercise, and vagal reactivation mediates the rate at which heart rate recovers after exercise (Freeman et al. 2006). Notably, the rate at which heart rate recovers from exercise (heart rate recovery, HRR) is associated with all-cause and cardiovascular mortality (Cole et al. 1999, 2000; Nishime et al. 2000).

There is evidence of a sustained increase in sympathetic activity and a reduction in parasympathetic input to the sino-atrial node in patients treated for early stage BC (Jones et al. 2012). Several studies have also shown that heart rate variability and baroreflex sensitivity is reduced among women with a history breast cancer (Meinardi et al. 2001).

This study tested the hypothesis that exercise training improves autonomic function as evaluated by HRR in BC women belonging to the DIANA (Diet and Androgens)- 5 cohort.

\section{Methods \\ Study population}

The DIANA (Diet and Androgens)- 5 study is a multicentre randomized controlled trial of the effectiveness of a diet based on Mediterranean and macrobiotic recipes and principles, associated with moderate physical activity, in reducing additional breast cancer $(B C)$ events in women with early stage invasive $\mathrm{BC}$ at high risk of recurrence because of metabolic or endocrine milieu (Villarini et al. 2012). The overall design of the study has been described elsewhere (Villarini et al. 2012). We analyzed monocentric data (University of Naples "Federico II") consisting of 51 patients randomized into two groups: 25 patients (51.8 \pm 7.7 years, training group) were assigned to a structured exercise training intervention (3 times/ week for the first 3 months, and once/week for the following 9 months); whereas 26 patients $(53.9 \pm 8.5$ years, control group) received only general recommendations to adhere to the life-style intervention suggestions of the DIANA protocol. Our institutional ethical committee approved the protocol. The purpose of the protocol was explained to the patients and written informed consent was obtained from each patient before inclusion.

\section{Study protocol}

At the study enrollment and after 12 months, all patients underwent anthropometrical and biochemical assessment, cardiovascular clinical examination, and cardiopulmonary exercise stress testing. Before randomization, all women received a leaflet illustrating the WCRF/AICR recommendations for cancer prevention (http://www. dietandcancerreport.org/cancer_prevention_recommendations/index.php). Training group patients were administered both the dietary and exercise training program as detailed below. After randomization, only the intervention group (training group, 25 patients) underwent, in addition to exercise training sessions, a counseling dietary program supported by cooking classes, reinforcing meetings and print materials. The counseling program aimed at increasing leisure-time physical activity level, controlling weight, and promoting a healthy and low calorie diet. Control group (26 patients) received only general recommendations on life-style.

\section{Anthropometrical and biochemical assessment}

Body mass index (BMI) was used as a general measure of obesity and was calculated at the final visit as weight ( $\mathrm{kg})$ divided by height $\left(\mathrm{m}^{2}\right)$. Waist circumference (WC), an index of abdominal obesity, was measured midway between the bottom of the rib cage and the top of the iliac crest. Blood pressure was measured twice after 5 min rest using a mercury sphygmomanometer. Anthropometric measurements were made with the subjects in indoor clothing and without shoes. Blood specimens were collected after 12- to 14-h fast, from 08:00 to 09:30 h, to reduce the influence of circadian variation. Total cholesterol, triglyceride and high-density lipoprotein (HDL) cholesterol levels were measured using standard enzymatic methods (Gentile et al. 2013). Low-density lipoprotein (LDL) cholesterol was calculated according to the Friedewald formula. Fasting glucose levels were enzymatically determined by the peroxidase method. Fasting insulin levels were determined by enzyme immunoassay (Ultrasensitive Insulin Elisa, Mercodia, Sweden). The homeostatic assessment model (HOMA) index was used to estimate insulin resistance and calculated as fasting serum insulin $(\mathrm{mU} / \mathrm{l}) \times$ fasting serum glucose $(\mathrm{mM}) / 22.5$, as previously described (Matthews et al. 1985).

\section{Cardiopulmonary exercise training testing}

Respiratory gas exchange measurements were obtained breath by breath with the use of a computerized metabolic cart (Vmax 29C, Sensormedics, Yorba Linda, CA, USA) as detailed elsewhere (Giallauria et al. 2006a, b). Briefly, after a 1-min warm-up period at $0 \mathrm{~W}$ workload, a ramp protocol of $20 \mathrm{~W} / \mathrm{min}$ was started and continued until exhaustion. The pedaling was kept constant at 55-65 revolutions/min. A 12-lead electrocardiogram (ECG) was monitored continuously during the test, and cuff blood pressure was manually recorded every $2 \mathrm{~min}$. $\mathrm{VO}_{2 \text { peak }}$ was recorded as the mean value of $\mathrm{VO}_{2}$ during the last $20 \mathrm{~s}$ of the test and was expressed in milliliters per kilogram per minute. Predicted $\mathrm{VO}_{2 \text { peak }}$ was determined 
by use of a sex-, age-, height- and weight-adjusted and protocol-specific formula as previously detailed (Giallauria et al. 2006a, b). The ventilatory anaerobic threshold (VAT) was detected by use of the V-slope method. The VE versus $\mathrm{VCO}_{2}$ relationship was measured by plotting ventilation (VE) against carbon dioxide production $\left(\mathrm{VCO}_{2}\right)$ obtained every $10 \mathrm{~s}$ of exercise $\left(\mathrm{VE} / \mathrm{VCO}_{2 \text { slope }}\right)$ : both $\mathrm{VE}$ and $\mathrm{VCO}_{2}$ were measured in liters per minute. The VE/ $/ \mathrm{VCO}_{2 \text { slope }}$ was calculated as a linear regression function, excluding the non-linear part of the relationship after the onset of acidotic drive to ventilation (Giallauria et al. 2006a, b). Heart rate (HR) and blood pressure (BP) at baseline and peak exercise, and heart rate during the cooling down phase after exercise were recorded. HRR was calculated as the difference between HR at peak exercise and heart rate at first minute of the cool-down period (Giallauria et al. 2008a, b).

\section{Exercise training program and cooking session}

Training group patients were enrolled in an in-hospital structured exercise training program. The frequency goals of in-hospital exercise training sessions was three times/week for the first 3 months, and once/week for the following 9 months. Each session consisted of cycle or treadmill 30 min exercise, preceded by 5 min of warming and followed by 5 min of cooling down, at a work load of $75 \%$ of baseline peak $\mathrm{VO}_{2}$. This structured exercise training was on top of the general leisure-time physical activity recommendations or prescription of the general DIANA study (questionnaires, caloric control, etc., see above). From the 4th month to the 12th month, inhospital exercise training sessions were reduced to one session/week, integrated with general leisure-time physical activity sessions, according to recommendations and prescription of the general DIANA study (Villarini et al. 2012). During cooking sessions, patients were invited cooking and eating some dishes prepared according to the WCRF/AICR recommendations and inspired by a macrobiotic Mediterranean diet (http://www.dietandcancerreport.org/cancer_prevention_recommendations/ index.php).

\section{Statistical methods}

Continuous variables were reported as either mean and standard deviation (SD) or median and range according to their distribution. The normality of residuals was tested with the Shapiro-Wilks test, and if residuals were not normally distributed the difference between HRR values was tested using the Wilcoxon test. Categorical variables were reported as percentage. Differences in characteristics of patients among groups were tested by means of one-way ANOVA and Pearson Chi square test for continuous and categorical variables, respectively.
Data were analyzed using SAS version 9.2 (SAS Inc, Cary, NC, USA). All statistical tests were two-sided and p-values $<0.05$ were considered significant.

\section{Results}

Baseline characteristics of the study population are shown in Table 1 . There were no significant differences between groups in baseline anthropometrical, $\mathrm{BC}$ characteristics and metabolic profile (Table 1).

The study period was similar in both groups. In training group, the average exercise intensity was $70 \pm 2 \%$ of baseline $\mathrm{VO}_{2 \text { peak }}$. No adverse events took place during any of training sessions in $\mathrm{BC}$ patients undergoing exercise training sessions.

Both groups were overweight at baseline (Table 1). At 1-year follow-up, a significant decrease in BMI (from $27.3 \pm 5.2$ to $26.6 \pm 4.9 \mathrm{~kg} / \mathrm{m}^{2}, \mathrm{p}=0.02$ ), in WC (from $94 \pm 15$ to $90 \pm 13 \mathrm{~cm}, \mathrm{p}=0.005$ ), and in systolic blood pressure (from $121 \pm 17$ to $115 \pm 12 \mathrm{mmHg}$, $\mathrm{p}=0.011$ ), while no changes were observed among controls (Table 2). Baseline plasma lipids, glucose and insulin levels were normal and did not change at 1 year in both groups.

No differences in baseline cardiopulmonary parameters were found (Table 2). At baseline $\mathrm{VO}_{2 \text { peak }}$ and $\mathrm{O}_{2}$-pulse were in the lower range (Weber class $\mathrm{C}$ ) in both groups. In ET group $\mathrm{VO}_{2 \text { peak }}$ (from $12.6 \pm 3.0$ to $14.5 \pm 3.3 \mathrm{ml} / \mathrm{kg} / \mathrm{min}, \mathrm{p}<0.001$ ) and $\mathrm{O}_{2}$-pulse (from $6.2 \pm 1.2$ to $6.9 \pm 1.2 \mathrm{ml} / \mathrm{kg} / \mathrm{min} /$ beat $-1, \mathrm{p}<0.001)$ improved at 1-year follow-up, respectively. No significant changes in $\mathrm{VO}_{\text {2peak }}(12.8 \pm 2.5$ to $12.6 \pm 2.8 \mathrm{ml} / \mathrm{kg} / \mathrm{min}$, $\mathrm{p}=0.55 ; \mathrm{p}<0.001$ between groups), and in $\mathrm{O}_{2}$-pulse (from $6.0 \pm 1.4$ to $6.2 \pm 1.2 \mathrm{ml} / \mathrm{kg} / \mathrm{min} /$ beat -1 , $\mathrm{p}=0.39$; $\mathrm{p}<0.001$ between groups) were observed at 1 -year follow-up among controls.

No significant differences in HRR were found among groups (Table 2). ET group showed a significant improvement of HRR (from $17.6 \pm 6.4$ to $23.0 \pm 8.3$ beats $/ \mathrm{min}$, $\mathrm{p}<0.001$ ); whereas no significant changes were observed among controls (from $16.4 \pm 7.7$ to $17.4 \pm 7.8$ beats $/ \mathrm{min}$, $\mathrm{p}=0.35 ; \mathrm{p}<0.001$ between groups).

At 1-year follow-up, the level of physical fitness achieved in ET group as expressed by $\mathrm{VO}_{2 \text { peak }}$ was inversely correlated with the 1-year value of $\mathrm{BMI}$ $(\mathrm{r}=-0.426, \mathrm{p}=0.001)$ and WC $(\mathrm{r}=-0.47, \mathrm{p}<0.001)$. In ET group the changes in HRR directly correlated with changes in $\mathrm{VO}_{\text {2peak }}(\mathrm{r}=0.58, \mathrm{p}=0.002)$.

\section{Discussion}

The main finding of this study is that structured exercise training improves autonomic function in women with early stage invasive $\mathrm{BC}$ at high risk of recurrence because of metabolic or endocrine milieu. 
Table 1 Anthropometrical and clinical characteristics of the study population

\begin{tabular}{|c|c|c|c|}
\hline & Training Group $(n=25)$ & Control Group $(n=26)$ & $P$ value \\
\hline \multicolumn{4}{|l|}{ Anthropometrics } \\
\hline Age (years) & $51.8 \pm 7.7$ & $53.9 \pm 8.5$ & 0.55 \\
\hline Waist circumference (cm) & $94 \pm 15$ & $94 \pm 12$ & 0.66 \\
\hline Body mass index $\left(\mathrm{kg} / \mathrm{m}^{2}\right)$ & $27.3 \pm 5.2$ & $28.2 \pm 4.8$ & 0.20 \\
\hline \multicolumn{4}{|l|}{ Breast cancer characteristics } \\
\hline Presence of invasive carcinoma (\%) & $25 / 25(100)$ & $26 / 26(100)$ & - \\
\hline Node positivity (\%) & $48(n=12 / 25)$ & $54(n=14 / 26)$ & 0.58 \\
\hline Estrogen positivity (\%) & $80(n=20 / 25)$ & $85(n=22 / 26)$ & 0.78 \\
\hline \multicolumn{4}{|l|}{ Metabolic and hormonal profile } \\
\hline Glycemia (mg/dl) & $93.5 \pm 12.5$ & $92.2 \pm 15.5$ & 0.67 \\
\hline Insulin (ng/ml) & $7.8 \pm 4.0$ & $8.2 \pm 2.2$ & 0.29 \\
\hline HOMA index & $1.739 \pm 1.403$ & $1.925 \pm 0.908$ & 0.54 \\
\hline Total cholesterol (mg/dl) & $205 \pm 34$ & $203 \pm 32$ & 0.85 \\
\hline LDL-cholesterol (mg/dl) & $126 \pm 35$ & $123 \pm 29$ & 0.24 \\
\hline HDL-cholesterol (mg/dl) & $54.3 \pm 11.6$ & $54.8 \pm 12.7$ & 0.63 \\
\hline Triglycerides (mg/dl) & $100 \pm 43$ & $109 \pm 52$ & 0.13 \\
\hline Testosterone (nmol/l) & $0.36 \pm 0.36$ & $0.38 \pm 0.26$ & 0.79 \\
\hline
\end{tabular}

HOMA homeostatic assessment model, LDL low-density lipoprotein, HDL high-density lipoprotein.

Table 2 Anthropometrics, metabolic and hormonal, cardiopulmonary and autonomic parameters

\begin{tabular}{|c|c|c|c|c|c|c|c|}
\hline & \multicolumn{2}{|c|}{ Trained group $(n=25)$} & \multirow[t]{2}{*}{$P$-value } & \multicolumn{2}{|c|}{ Control group $(n=26)$} & \multirow[t]{2}{*}{$P$-value } & \multirow{2}{*}{$\begin{array}{l}\text { Differences in } \\
\text { changes between } \\
\text { groups }\end{array}$} \\
\hline & Baseline & 1-year & & Baseline & 1-year & & \\
\hline \multicolumn{8}{|l|}{ Anthropometrics } \\
\hline Waist circumference (cm) & $94 \pm 15$ & $90 \pm 13$ & 0.005 & $94 \pm 12$ & $95 \pm 12$ & 0.88 & $<0.001$ \\
\hline Body mass index $\left(\mathrm{kg} / \mathrm{m}^{2}\right)$ & $27.3 \pm 5.2$ & $26.6 \pm 4.9$ & 0.02 & $28.2 \pm 4.8$ & $28.3 \pm 5.4$ & 0.67 & $<0.001$ \\
\hline \multicolumn{8}{|l|}{ Metabolic and hormonal profile } \\
\hline Glycemia (mg/dl) & $93.5 \pm 12.5$ & $92.8 \pm 13$ & 0.61 & $92.2 \pm 15.5$ & $90.6 \pm 18.1$ & 0.63 & 0.44 \\
\hline Insulin (ng/ml) & $7.8 \pm 4.0$ & $8.0 \pm 5.0$ & 0.74 & $8.2 \pm 2.2$ & $7.9 \pm 3.1$ & 0.71 & 0.88 \\
\hline HOMA index & $1.739 \pm 1.403$ & $1.822 \pm 0.629$ & 0.51 & $1.925 \pm 0.908$ & $1.825 \pm 0.477$ & 0.61 & 0.77 \\
\hline Total cholesterol (mg/dl) & $205 \pm 34$ & $200 \pm 29$ & 0.66 & $203 \pm 32$ & $210 \pm 26$ & 0.42 & 0.62 \\
\hline LDL-cholesterol (mg/dl) & $126 \pm 35$ & $122 \pm 30$ & 0.36 & $123 \pm 29$ & $126 \pm 35$ & 0.22 & 0.29 \\
\hline HDL-cholesterol (mg/dl) & $54.3 \pm 11.6$ & $55.5 \pm 9.7$ & 0.78 & $54.8 \pm 12.7$ & $50.1 \pm 8.7$ & 0.19 & 0.52 \\
\hline Triglycerides (mg/dl) & $100 \pm 43$ & $108 \pm 42$ & 0.53 & $109 \pm 52$ & $119 \pm 46$ & 0.60 & 0.41 \\
\hline Testosterone (nmol/l) & $0.36 \pm 0.36$ & $0.40 \pm 0.16$ & 0.21 & $0.38 \pm 0.26$ & $0.33 \pm 0.19$ & 0.49 & 0.42 \\
\hline \multicolumn{8}{|l|}{ Cardiopulmonary parameters } \\
\hline $\mathrm{VO}_{2 \text { peak }}(\mathrm{ml} / \mathrm{kg} / \mathrm{min})$ & $12.6 \pm 3.0$ & $14.5 \pm 3.3$ & $<0.001$ & $12.8 \pm 2.5$ & $12.6 \pm 2.8$ & 0.55 & $<0.001$ \\
\hline $\mathrm{O}_{2}$-pulse $(\mathrm{ml} / \mathrm{kg} / \mathrm{min} /$ beat-1) & $6.2 \pm 1.2$ & $6.9 \pm 1.2$ & $<0.001$ & $6.0 \pm 1.4$ & $6.2 \pm 1.2$ & 0.39 & $<0.001$ \\
\hline VENCO 2 slope & $29.7 \pm 4.4$ & $30.9 \pm 3.9$ & 0.12 & $30.1 \pm 3.8$ & $31.3 \pm 4.9$ & 0.46 & 0.44 \\
\hline \multicolumn{8}{|l|}{ Autonomic function } \\
\hline Heart rate recovery & $17.6 \pm 6.4$ & $23.0 \pm 8.3$ & $<0.001$ & $16.4 \pm 7.7$ & $17.4 \pm 7.8$ & 0.35 & $<0.001$ \\
\hline
\end{tabular}

HOMA homeostatic assessment model, $L D L$ low-density lipoprotein, $H D L$ high-density lipoprotein, $V E / V C O_{2 s l o p e}$ the minute ventilation-carbon dioxide production, $\mathrm{VO}_{\text {2peak }}$ peak oxygen consumption.

Mounting evidences suggest that long-term autonomic imbalance is associated with increased risk of CVD and mortality in non-cancer populations (Cole et al. 1999,
2000; Nishime et al. 2000). There is evidence of a sustained increase in sympathetic activity and a reduction in parasympathetic input to the sino-atrial node in patients 
treated for early stage BC. The resting HR of early stage $\mathrm{BC}$ patients following the completion of primary adjuvant therapy is, on average, $9-16 \%$ higher compared to age-matched controls (Jones et al. 2012). Several studies have also shown that heart variability and baroreflex sensitivity is reduced among women with a history breast cancer (Meinardi et al. 2001). Accordingly, based on a growing understanding of bi-directional interactions between the sympathetic and parasympathetic efferent pathways, autonomic imbalance is one potential pathway involved in both the etiology and the clinical course of breast cancer therapy-induced CVD.

Despite the potential long-term consequences of autonomic dysfunction in women with $\mathrm{BC}$, the development of safe and effective therapeutic strategies remains still elusive. Exercise training is one non-pharmacological therapy that may improve cardiovascular risk profile in the early $\mathrm{BC}$ setting; however, the mechanisms by which ET mitigates autonomic dysfunction are not fully understood. There is some clue that the central pathways responsible for decreasing sympathetic outflow and increasing cardiac vagal tone after ET are, in part, dependent on changes in the renin-angiotensin-aldosterone system (RAAS), nitric oxide (NO), and reactive oxygen species (ROS) (Scott et al. 2014). The signaling pathway RAAS plays a pivotal role in chemotherapy induced cardiotoxicity (Cadeddu et al. 2010). Since angiotensin II exerts powerful inhibitory effects upon the cardiac vagus nerve, its suppression or a precursor via ET could ultimately play an important role in the prevention of cardiac dysfunction. Breast cancer therapies also inhibit vascular NO release, consequently promoting vasoconstriction, increased peripheral resistance, and increased blood pressure (Facemire et al. 2009). Thus the up-regulation of NO with ET could improve autonomic function. Interestingly, there is evidence that ET improves peripheral arterial endothelial function (a surrogate measure of $\mathrm{NO}$ bioavailability) in women with operable $\mathrm{BC}$ receiving neoadjuvant doxorubicin (Jones et al. 2013). Finally, chemotherapy-induced generation of reactive oxygen species (ROS) is the central mediator of several adverse acute and chronic biological effects in the cardiovascular system, including alterations in autonomic outflow (Minotti et al. 2004). Accordingly, attenuation of ROS generation and/or activity holds considerable therapeutic promise. A recent study found that ET during chronic anthracyclines exposure in mice reduced serum and cardiac levels of ROS and attenuated LV remodeling suggesting a protective role of ET of cardiac cells against chemotherapy-induced toxicity through ROS inhibition (Dolinsky et al. 2013).

The nervous system plays a significant role in control of cancer growth and metastasis (Ondicova and Mravec
2010). Stress causes alterations in the immune system, the neuroendocrine system and sensory nerve functions, which in turn could contribute to cancer mortality (Erin et al. 2004a, b, 2006; Ercan et al. 2006; Spiegel et al. 1998). Stressful life events can accelerate the progression of existing cancer (Chida et al. 2008). How cancer-induced systemic changes, as well as stress of the disease, alter neuroimmune functions is not fully understood. Interestingly, the adrenal gland, due to its centrality on the hypothalamus, pituitary, and adrenal gland neuroendocrine axis, plays a crucial role in regulation of the stress response by providing a link between the neuroendocrine and immune systems. There is evidence that adrenal response to certain cytokines is suppressed in patients with cancer, which may alter appropriate immune response. The vagus nerve and capsaicin-sensitive sensory neurons seem to play a crucial role in the regulation of adrenal functions, as well as the immune system. Stimulation of the vagus nerve increases the activity of nerve fibers innervating the adrenal medulla (Niijima 1992). Inactivation of capsaicin-sensitive sensory nerve fibers increases post-stress plasma cortisone levels (Ulrich-Lai et al. 2003). In addition, epinephrine released from the adrenal medulla increases the activity of afferent vagal fibers, and these fibers may in turn influence the activity of sympathetic nerves modulating the release of epinephrine, as well as the stress response (Mravec et al. 2006). The vagus nerve also directly regulates the immune system, such that activation of the vagus nerve inhibits the inflammatory response (Zracey 2002) and alters (CD4)+ $\mathrm{T}$ cell functions (Karimi et al. 2010). In an elegant study, Erin et al. (2013) showed that vagotomy enhances adrenal metastasis. Interestingly, the layer most affected by the tumor burden was the medulla, thus resulting in sympathetic deregulation, and consequently immune dysfunction, and in turn further enhancing the metastatic ability of the carcinoma. Therefore, the vagus nerve plays a significant role in defense against cancer by inhibiting cancer metastasis. Since there is strong evidence that lifestyle modification (diet and physical activity) have positive impact on cancer outcomes (Mishra et al. 2012), the improvement of sympatho-vagal balance might be at the basis of these beneficial prognostic effects.

Mounting evidences showed that despite normal cardiac function, BC women have significant and marked impairments in cardiopulmonary function (Jones et al. 2012; Sweeney et al. 2006). Notably, we found that baseline $\mathrm{VO}_{2 \text { peak }}$ and $\mathrm{O}_{2}$-pulse values were in the lower range (Weber class $\mathrm{C}$ ) in both cohorts; however, $\mathrm{BC}$ women undergoing ET significantly improved their cardiopulmonary functional capacity. There is solid evidence that the level of physical exercise is associated to improved outcome in $\mathrm{BC}$ patients, included 
cancer related and total mortality (Ballard-Barbash et al. 2012). Therefore, the present study adds to the growing literature for exercise training as a valid, safe and additive therapeutic strategy in cancer patients.

Some limitations of the present study should be considered. The present study was not designed at evaluating cancer outcomes (i.e. mortality, recurrences). In addition, training patients underwent moderate intensity exercise program: whether an exercise program of higher intensity might have additional clinical and prognostic value should be clarified. Despite the aforementioned limitations, this study has several unique strengths. This is the first study enrolling high-risk BC survivors (women with early stage invasive $B C$ at high risk of recurrence because of metabolic or endocrine milieu) to 1-year exercise intervention showing significant improvement of autonomic function.

\section{Conclusions}

In conclusion, moderate intensity exercise training in $\mathrm{BC}$ survivors improves autonomic and cardiopulmonary function. Whether the improvement of sympatho-vagal balance may favorably modulate some of the pathophysiological mechanisms implied in cancer evolution need further investigation.

\begin{abstract}
Authors' contributions
$\mathrm{FG}, \mathrm{CV}, \mathrm{FB}$ and SP were involved in the conception and design, acquisition of data, analysis and interpretation of data; drafting the manuscript or revising it critically for important intellectual content; final approval of the version to be published; and agree to be accountable for all aspects of the work in ensuring that questions related to the accuracy or integrity of any part of the work are appropriately investigated and resolved. MSDM performed nutritional assessment and supervised cooking sessions. MM, AG, AR, RL, GT performed cardiopulmonary exercise testing and supervised exercise training programs and cooking sessions. PC, AM, MG, LM and AV participated in the design of the study and performed the statistical analysis. FG, CV, FB and SP conceived of the study, and participated in its design and coordination and helped to draft the manuscript. All authors read and approved the final manuscript.
\end{abstract}

\section{Author details}

${ }^{1}$ Division of Internal Medicine and Cardiac Rehabilitation, Department of Translational Medical Sciences, University of Naples "Federico II", Via S. Pansini 5, 80131 Naples, NA, Italy. ${ }^{2}$ Dipartimento di Medicina Clinica e Chirurgia, Federico II University, Naples, Italy. ${ }^{3}$ Medical Statistics Unit, Second University of Naples, Naples, Italy. ${ }^{4}$ Department of Preventive and Predictive Medicine, National Cancer Institute, Milan, Italy.

\section{Acknowledgements}

The DIANA-5 Project was financed by the Italian Association for Cancer Research (AIRC, Grant no 11942) and by the Italian Department of Health (PIO program). This study was also financed by the FARO (Fondo per I'Avvio di Ricerche Originali).

\section{Compliance with ethical guidelines}

\section{Competing interests}

The authors declare that they have no competing interests.

Received: 22 July 2015 Accepted: 23 July 2015

Published online: 01 August 2015

\section{References}

(2015) http://www.ncbi.nlm.nih.gov/pubmed/?term=diet+and+breast + can cer+and+meta-analysis. Accessed 5 June 2015

(2015) http://www.ncbi.nlm.nih.gov/pubmed/?term=physical+activity+and +breast+cancer+and+meta-analysis. Accessed 5 June 2015

(2015) http://www.dietandcancerreport.org/cancer_prevention_recommendations/index.php. Accessed 5 June 2015

Ballard-Barbash R, Friedenreich CM, Courneya KS, Siddiqi SM, McTiernan A, Alfano CM (2012) Physical activity, biomarkers, and disease outcomes in cancer survivors: a systematic review. J Natl Cancer Inst 104:815-840

Buckland G, Travier N, Cottet $\mathrm{V}$ et al (2013) Adherence to the mediterranean diet and risk of breast cancer in the European prospective investigation into cancer and nutrition cohort study. Int J Cancer 132:2918-2927

Cadeddu C, Piras A, Mantovani G et al (2010) Protective effects of the angiotensin II receptor blocker telmisartan on epirubicin-induced inflammation, oxidative stress, and early ventricular impairment. Am Heart J 160(3):487.e1-7

Chida Y, Hamer M, Wardle J, Steptoe A (2008) Do stress-related psychosocial factors contribute to cancer incidence and survival? Nat Clin Pract Oncol 5:466-475

Cole CR, Blackstone EH, Pashkow FJ, Snader CE, Lauer MS (1999) Heart-rate recovery immediately after exercise as a predictor of mortality. $N$ Engl J Med 341:1351-1357

Cole CR, Foody JM, Blackstone EH, Lauer MS (2000) Heart rate recovery after submaximal exercise testing as a predictor of mortality in a cardiovascularly healthy cohort. Ann Intern Med 132:552-555

Dolinsky VW, Rogan KJ, Sung MM et al (2013) Both aerobic exercise and resveratrol supplementation attenuate doxorubicin-induced cardiac injury in mice. Am J Physiol Endocrinol Metab 305(2):E243-E253

Erin N, Ersoy Y, Ercan F, Akici A, Oktay S (2004a) NK-1 antagonist CP99994 inhibits stress-induced mast cell degranulation in rats. Clin Exp Dermatol 29:644-648

Erin N, Boyer PJ, Bonneau RH, Clawson GA, Welch DR (2004b) Capsaicinmediated denervation of sensory neurons promotes mammary tumor metastasis to lung and heart. Anticancer Res 24:1003-1009

Ercan F, Akici A, Ersoy Y, Hurdag C, Erin N (2006) Inhibition of substance P activity prevents stress-induced bladder damage. Regul Pept 133:82-89

Erin N, Zhao W, Bylander J, Chase G, Clawson G (2006) Capsaicin-induced inactivation of sensory neurons promotes a more aggressive gene expression phenotype in breast cancer cells. Breast Cancer Res Treat 99:351-364

Erin N, Barkan GA, Clawson GA (2013) Vagus nerve regulates breast cancer metastasis to the adrenal gland. Anticancer Res 33:3675-3682

Facemire CS, Nixon AB, Griffiths R, Hurwitz H, Coffman TM (2009) Vascular endothelial growth factor receptor 2 controls blood pressure by regulating nitric oxide synthase expression. Hypertension 54(3):652-658

Ferrari P, Rinaldi S, Jenab M et al (2013) Dietary fiber intake and risk of hormonal receptor-defined breast cancer in the European prospective investigation into cancer and nutrition study. Am J Clin Nutr 97:344-353

Freeman JV, Dewey FE, Hadley DM, Myers J, Froelicher VF (2006) Autonomic nervous system interaction with the cardiovascular system during exercise. Prog Cardiovasc Dis 48:342-362

Gentile M, Panico S, Mattiello A et al (2013) Association between small dense $\mathrm{LDL}$ and early atherosclerosis in a sample of menopausal women. Clin Chim Acta 426:1-5

Giallauria F, Lucci R, Pietrosante M, De Lorenzo A, Gargiulo G, D'Agostino M et al (2006a) Exercise-based cardiac rehabilitation improves heart rate recovery in elderly patients after acute myocardial infarction. J Gerontol Ser A Biol Sci Med Sci 61(7):713-717

Giallauria F, De Lorenzo A, Pilerci F, Manakos A, Lucci R, Psaroudaki M et al (2006b) Long-term effects of cardiac rehabilitation on end-exercise heart rate recovery after myocardial infarction. Eur J Cardiovasc Prev Rehabil 13(4):544-550

Giallauria F, Palomba S, Cascella T, Manguso F, Vitelli A, Maresca L et al (2008a) Abnormal heart rate recovery after maximal cardiopulmonary exercise stress testing in young women with polycystic ovary syndrome. Clin Endocrinol (Oxf) 68(1):88-93

Giallauria F, Palomba S, Maresca L, Vuolo L, Tafuri D, Lombardi G et al (2008b) Exercise training improves autonomic function and inflammatory pattern in women with polycystic ovary syndrome. Clin Endocrinol (Oxf) 69(5):792-798 
Gleeson M, Bishop NC, Stensel DJ, Lindley MR, Mastana SS, Nimmo MA (2011) The anti-inflammatory effects of exercise: mechanisms and implications for the prevention and treatment of disease. Nat Rev Immunol 11:607-615

Goh J, Kirk EA, Lee SX, Ladiges WC (2012) Exercise, physical activity and breast cancer: the role of tumor-associated macrophages. Exerc Immunol Rev 18:158-176

Ibrahim EM, Al Homaidh A (2011) Physical activity and survival after breast cancer diagnosis: meta-analysis of published studies. Med Oncol 28:753-765

Jones LW, Courneya KS, Mackey JR, Muss HB, Pituskin EN, Scott JM et al (2012) Cardiopulmonary function and age-related decline across the breast cancer survivorship continuum. J Clin Oncol 30:2530-2537

Jones LW, Fels DR, West M et al (2013) Modulation of circulating angiogenic factors and tumor biology by aerobic training in breast cancer patients receiving neoadjuvant chemotherapy. Cancer Prev Res 6:925-937

Karimi K, Bienenstock J, Wang L, Forsythe P (2010) The vagus nerve modulates CD4+ T cell activity. Brain Behav Immun 24:316-323

Matthews DR, Hosker JP, Rudenski AS, Naylor BA, Treacher DF, Turner RC (1985) Homeostasis model assessment: insulin resistance and beta-cell function from fasting plasma glucose and insulin concentrations in man. Diabetologia 28:412-419

McTiernan A (2008) Mechanisms linking physical activity with cancer. Nat Rev Cancer 8:205-211

Meinardi MT, van Veldhuisen DJ, Gietema JA et al (2001) Prospective evaluation of early cardiac damage induced by epirubicin-containing adjuvant chemotherapy and locoregional radiotherapy in breast cancer patients. J Clin Oncol 19:2746-2753

Minotti G, Menna P, Salvatorelli E, Cairo G, Gianni L (2004) Anthracyclines: molecular advances and pharmacologic developments in antitumor activity and cardiotoxicity. Pharmacol Rev 56:185-229
Mishra SI, Scherer RW, Snyder C, Geigle PM, Berlanstein DR, Topaloglu O (2012) Exercise interventions on health-related quality of life for people with cancer during active treatment. Cochrane Database Syst Rev 8:CD008465

Mravec B, Gidron Y, Kukanova B, Bizik J, Kiss A, Hulin I (2006) Neural-endocrineimmune complex in the central modulation of tumorigenesis: facts, assumptions, and hypotheses. J Neuroimmunol 180:104-116

Niijima A (1992) Electrophysiological study on the vagal innervation of the adrenal gland in the rat. J Auton Nerv Syst 41:87-92

Nishime EO, Cole CR, Blackstone EH, Pashkow FJ, Lauer MS (2000) Heart rate recovery and treadmill exercise score as predictors of mortality in patients referred for exercise ECG. JAMA 284:1392-1398

Ondicova K, Mravec B (2010) Role of nervous system in cancer aetiopathogenesis. Lancet Oncol 11:596-601

Scott JM, Jones LW, Hornsby WE, Koelwyn GJ, Khouri MG, Joy AA et al (2014) Cancer therapy-induced autonomic dysfunction in early breast cancer: implications for aerobic exercise training. Int J Cardiol 171:e50-e51

Spiegel D, Sephton SE, Terr Al, Stites DP (1998) Effects of psychosocial treatment in prolonging cancer survival may be mediated by neuroimmune pathways. Ann NY Acad Sci 840:674-683

Spence RR, Heesch KC, Brown WJ (2010) Exercise and cancer rehabilitation: a systematic review. Cancer Treat Rev 36:185-194

Sweeney C, Schmitz KH, Lazovich D (2006) Functional limitations in elderly female cancer survivors. J Natl Cancer Inst 98:521-529

Ulrich-Lai YM, Fraticelli Al, Engeland WC (2003) Capsaicinsensitive nerve fibers: a potential extra-ACTH mechanism participating in adrenal regeneration in rats. Microsc Res Tech 61:252-258

Villarini A, Pasanisi P, Traina A et al (2012) Lifestyle and breast cancer recurrences: the DIANA-5 trial. Tumori 98:1-18

Zracey KJ (2002) The inflammatory reflex. Nature 420:853-859

\section{Submit your manuscript to a SpringerOpen ${ }^{\circ}$ journal and benefit from:}

- Convenient online submission

- Rigorous peer review

- Immediate publication on acceptance

- Open access: articles freely available online

- High visibility within the field

- Retaining the copyright to your article

Submit your next manuscript at $>$ springeropen.com 